\title{
OS SUPERMERCADOS E O PEQUENO COMÉRCIO. TRANSFORMAÇÕES E RESISTÊNCIAS NUMA CIDADE MÉDIA DO NORDESTE BRASILEIRO SOBRAL - CEARÁ*
}

Lenilton Francisco de Assis ${ }^{1}$ Antonia Helaine Veras Rodrigues ${ }^{2}$

\begin{abstract}
Resumo - Este artigo discute as transformações que os supermercados vêm engendrando no espaço urbano de Sobral, cidade média do Nordeste brasileiro. Uma reestruturação intra-urbana se inicia em Sobral com a descentralização das atividades terciárias e a formação de novas centralidades nos bairros onde os supermercados foram instalados. As novas centralidades aumentam a segregação entre pobres e ricos e seus espaços de moradia e consumo na cidade. Os supermercados também têm acirrado a concorrência com os pequenos comércios do seu entorno, os quais já registram uma queda acentuada nas vendas. Porém, os pequenos comerciantes consideram inevitável a chegada de grandes unidades comerciais na cidade, restando a eles buscar estratégias e apoios que possam driblar a concorrência e garantir suas sobrevivências.
\end{abstract}

Palavras-chave: Supermercado, comércio tradicional, cidade média, espaço urbano, Sobral.

\begin{abstract}
Supermarkets AND SMALl RETAIL: CHANGE AND RESISTANCE IN A medium-Sized City in Northeast Brazil - Sobral (State of CearÁ). This article discusses the changes that supermarkets have been giving rise to in urban Sobral, a medium-sized city located in Northeast Brazil. In Sobral, the process of intra-urban restructuring has been largely driven by the relocation of tertiary activities away from the traditional centre and by the creation of new centralities in the neighborhoods where supermarkets have opened their doors. These new centralities have increased the level of segregation between the rich and the poor, as well as between their respective residential and consumption spaces in the city. In addition to this, supermarkets have also significantly increased the degree of competition faced by small retail, and caused the latter to experience a considerable drop in sales in recent times. Still, small retailers consider that the arrival of large-scale retail outlets in the city is inevitable,
\end{abstract}

* Recebido: 8/04/2008. Revisto: 16/09/2008; 22/09/2008. Aceite: 7/10/2008.

1 Professor Assistente do Curso de Geografia da UVA (Sobral/CE); Doutorando em Geografia Humana na USP; Bolsista do CNPq - Brasil. lenilton@yahoo.com

2 Aluna do Curso de Geografia da UVA (Sobral/CE); bolsista de Iniciação Científica da FUNCAP e do NEURB. helainevr@yahoo.com.br 
and that their only option is to pursue strategies and look for forms of support that will enable them to overcome their competition and ensure their livelihood. Sobral.

Key words: Supermarket, traditional commerce, medium-sized city, urban space,

Résumé - Les SuPERMARChÉS ET LE PETIT COMMERCE. TRANSFORMATIONS ET RÉSISTANCES DANS UNE VILle moYenne du Nordeste bRÉSILIEN, Sobral (CEARÁ). L'installation de supermarchés provoque la décentralisation des activités tertiaires, accompagnée de la formation de nouvelles centralités dans les quartiers d'accueil. Ces nouvelles centralités augmentent la ségrégation entre les espaces d'habitation et de consommation des pauvres et des riches. Les supermarchés rendent aussi plus aigüe la concurrence avec les petits commerces voisins, qui enregistrent déjà une chute sensible de leurs ventes. Ceux-ci savent cependant que l'arrivée des grandes unités de vente est inévitable et que l'unique remède est, pour eux, de trouver les stratégies et appuis leur permettant de contourner la concurrence, afin de survivre.

Mots-clés: Supermarché, commerce traditionnel, ville moyenne, espace urbain, Sobral.

\section{INTRODUÇÃO}

O comércio sempre foi um importante fator de crescimento e de organização das cidades, abarcando desde as "tradicionais" feiras livres aos "modernos" shopping centers. Essa coexistência do "tradicional" e do "moderno", é uma das principais características das redes varejistas dos países subdesenvolvidos, apontada por Santos (1979) no seu clássico estudo sobre os dois circuitos (superior e inferior) da economia urbana ${ }^{3}$.

Nas cidades médias brasileiras, as desigualdades dos dois circuitos se manifestam na paisagem urbana, revelando temporalidades e espacialidades distintas entre as grandes superfícies comerciais que se instalam (como os supermercados, hipermercados e shopping centers, "típicos" das metrópoles) e o pequeno comércio que "resiste", demarcando um outro tempo e cotidiano que são mais comuns nas cidades pequenas.

Em Sobral, cidade média do noroeste cearense, os supermercados Pinheiro e Super Lagoa são as mais "modernas" formas comerciais que têm atraído a descentralização de algumas atividades terciárias e influenciado no crescimento da cidade.

3 Santos (1979, p. 30) justifica que prefere as expressões "circuito superior" e "circuito inferior" ao invés de "circuito moderno" e "circuito tradicional" pelo fato dessas últimas já serem muito carregadas de significados e, sobretudo por considerar o "circuito inferior" também um produto da modernização. Compartilhando dessa visão do autor, mesmo sem aprofundá-la no presente trabalho, usaremos doravante as expressões "tradicional" e "moderno" sempre em destaque para reforçar as limitações dos seus significados. 
Os supermercados alteram as duas escalas da centralidade urbana, provocando, de um lado, a fragmentação do espaço intra-urbano contribuindo, do outro, para ampliar as relações de Sobral com os pequenos municípios que compõem a rede urbana regional (Assis et al., 2007).

Neste artigo $^{4}$, enfatizaremos a primeira escala de análise, no intuito de compreendermos as transformações que os supermercados vêm provocando no espaço urbano de Sobral, através da criação de novas centralidades e da concorrência com o pequeno comércio local.

A pesquisa incluiu uma revisão bibliográfica sobre a descentralização do comércio e o surgimento dos supermercados, o que nos deu subsídios para traçarmos os roteiros das pesquisas de campo, onde fizemos observações diretas, coletamos informações e aplicamos entrevistas semi-estruturadas com as gerências do Pinheiro e do Super Lagoa e com catorze pequenos comerciantes das avenidas onde esses supermercados foram instalados.

\section{A DESCENTRALIZAÇÃO DO COMÉRCIO E O SURGIMENTO DOS SUPERMERCADOS}

As atividades comerciais tendem a se localizar na área central da cidade, pois é para esta que convergem os fluxos intra e inter-urbanos. A área central é a projeção concreta da centralidade, da materialização da cidade em um ponto central (Corrêa, 2002).

Contudo, diversos fatores (dentre os quais o elevado preço da terra e os freqüentes congestionamentos) contribuem para que o aumento da centralização também provoque um processo contrário - a descentralização. Esta representa um meio de se manter uma taxa de lucro que a exclusiva localização central não é mais capaz de fornecer, gerando, por conseguinte, a formação de subcentros periféricos.

Strohaecker (1988: 175) ao analisar a gênese da zona periférica ao centro explica que:

"[...] atividades mais "limpas" como o comércio varejista e serviços tendem a se deslocar para as novas áreas onde o capital imobiliário produz habitações para as classes média e alta. Enquanto isso, as atividades financeiras e comércio mais especializado tendem a permanecer na área central pela capacidade em arcar com os altos custos do solo e tolerar inconvenientes como congestionamentos de tráfego, poluição e serviços públicos saturados."

4 Pesquisa realizada, entre 2006 e 2008, no Núcleo de Estudos Urbanos e Regionais (NEURB) do Curso de Geografia da Universidade Estadual Vale do Acaraú (UVA - Sobral/CE), com o apoio da Fundação Cearense de Apoio ao Desenvolvimento Científico e Tecnológico (FUNCAP). 
Deste modo, o espaço urbano se torna mais complexo com a descentralização das atividades terciárias e a gradativa formação de uma rede hierárquica de centros na zona periférica da cidade. Além de hierarquizados, os núcleos secundários tendem a apresentar algumas segmentações de mercado (como ruas de autopeças, de confecções, distritos médicos, etc.) que, no entanto, passam a dividir o mesmo espaço com atividades informais como o comércio ambulante e os transportes alternativos, entre outras.

Corrêa (2001: 48) ressalta que o processo de descentralização e suas respectivas formas espaciais é ainda mais amplo. A descentralização espacial de algumas atividades não representa, necessariamente, uma desconcentração do capital, mas a sua reconcentração monopolista nas mãos de poucos empresários ou grandes grupos varejistas que passam a concorrer com o pequeno comércio de bairro, levando à redução da sua importância ou até ao seu desaparecimento.

As "modernas" formas comerciais (como os supermercados, os hipermercados e os shopping centers) já surgem com uma forte tendência à descentralização, enquanto o comércio "tradicional" das feiras livres e dos mercados públicos permanece, com mais freqüência, no núcleo da cidade.

Além da localização, outras dimensões de análise diferenciam o comércio "tradicional" e o comércio "moderno", conforme apresentamos no quadro I:

Os supermercados, por exemplo, são algumas dessas "modernas" formas comerciais que alteram os hábitos de consumo das cidades e geram impactos diretos no funcionamento do comércio "tradicional". Eles surgiram na década de 1920, nos Estados Unidos, inaugurando a prática do auto-serviço (Silva, 2003), da escolha da mercadoria sem a intermediação do vendedor e do seu conhecido balcão.

Segundo Borges (2006), a Associação Brasileira de Supermercados (ABRAS), diferencia desde 1998, as lojas de auto-serviço pelo tamanho da área de vendas. $\mathrm{Na}$ classificação da ABRAS, os supermercados convencionais têm área de venda de 700 a $2.500 \mathrm{~m}^{2}$ e média de 9.000 itens ofertados. Têm normalmente cinco seções (mercearia, carne, frutas e verduras, frios e lacticínios, não-alimentos), $\mathrm{e}$, às vezes, padaria. Já os hipermercados, possuem dimensões acima de $5.000 \mathrm{~m}^{2}$ e operam com cerca de 35.000 itens, com linha completa de alimentação e quase completa de não-alimentos.

No Brasil, os primeiros supermercados foram instalados em 1953, na cidade de São Paulo, onde Pintaudi (1981: 45) detectou que:

"O abastecimento dos habitantes da cidade em gêneros alimentícios era feito através de um comércio de vizinhança: feiras-livres, quitanda, frutaria, açougue, padaria, armazém e mercearia, principalmente. Hoje em dia, este comércio, que era de caráter difuso, mostra uma tendência à concentração tanto espacial quanto financeira, através do Supermercado ${ }^{5}$."

5 Em trabalho mais recente, a autora também inclui na sua análise outras "modernas" formas de comércio como os Hipermercados e os Shopping Centers (Pintaudi, 2002). 
Quadro I - Características do comércio "tradicional" e "moderno"

Table I - Characteristics of "traditional" and "modern" retail

\begin{tabular}{|c|c|c|}
\hline \multicolumn{3}{|c|}{ Atributos do Comércio Varejista } \\
\hline Dimensões da análise & "Tradicional" & "Moderno" \\
\hline Formatos das lojas & $\begin{array}{l}\text { Pequenas lojas generalistas } \\
\text { Pequenas lojas especializadas } \\
\text { Mercados } \\
\text { Feiras } \\
\text { Grandes armazéns } \\
\text { Galerias comerciais }\end{array}$ & $\begin{array}{l}\text { Grandes superfícies de dominante } \\
\text { alimentar: supermercados, } \\
\text { hiper-mercados, lojas de desconto } \\
\text { Grandes superfícies especializadas } \\
\text { Centros comerciais } \\
\text { Megastores } \\
\text { Lojas de conveniência }\end{array}$ \\
\hline Formas de venda & $\begin{array}{l}\text { Venda ao balcão } \\
\text { Relação estreita entre comerciante } \\
\text { e consumidor } \\
\text { Venda ambulante }\end{array}$ & $\begin{array}{l}\text { Livre serviço } \\
\text { Venda automática } \\
\text { Venda à distância } \\
\text { Lojas virtuais }\end{array}$ \\
\hline Tipos de comerciantes & $\begin{array}{l}\text { Pequenos retalhistas } \\
\text { Comerciantes independentes } \\
\text { Pequenas empresas } \\
\text { (mono-estabelecimento) }\end{array}$ & $\begin{array}{l}\text { Grandes cadeias de distribuição } \\
\text { Sistema de franchising } \\
\text { Redes sucursalistas } \\
\text { Sociedades por cotas e anônimas }\end{array}$ \\
\hline $\begin{array}{l}\text { Estratégias de gestão } \\
\text { das empresas }\end{array}$ & $\begin{array}{l}\text { Predomínio da gestão familiar } \\
\text { Estratégias de gestão passivas e reativas } \\
\text { Ausência de estratégias de crescimento } \\
\text { bem definidas }\end{array}$ & $\begin{array}{l}\text { Gestão estratégica (capitalista) } \\
\text { Estratégias reativas e proativas } \\
\text { Procura de economias de escala } \\
\text { Redução dos custos } \\
\text { Diversificação dos formatos } \\
\text { Diferenciação da oferta } \\
\text { Conquista de novos mercados }\end{array}$ \\
\hline $\begin{array}{l}\text { Localização: } \\
\text { lugares e princípios }\end{array}$ & $\begin{array}{l}\text { Centro da cidade } \\
\text { Artérias principais da cidade } \\
\text { Bairros residenciais } \\
\text { Proximidade (vizinhança) } \\
\text { Centralidade } \\
\text { Conveniência (proximidade) }\end{array}$ & $\begin{array}{l}\text { Periferia } \\
\text { Centro da cidade } \\
\text { Grandes artérias urbanas } \\
\text { Acessibilidade } \\
\text { Facilidade de estacionamento } \\
\text { Conveniência (horários flexíveis) }\end{array}$ \\
\hline Significado das lojas & $\begin{array}{l}\text { Espaços de trocas } \\
\text { Lugares de compras/ abastecimento } \\
\text { Espaços mono-funcionais }\end{array}$ & $\begin{array}{l}\text { Espaços "mercadoria" } \\
\text { Lugares de experiências de consumo } \\
\text { Espaços de "síntese" }\end{array}$ \\
\hline
\end{tabular}

Fonte: Adaptado de Fernandes et al. (2000, p. 14).

A localização dos primeiros supermercados na metrópole paulistana foi motivada por alguns fatores, tais como: a existência de áreas com alta densidade demográfica, população com alto poder aquisitivo e boa malha viária que facilitava o acesso de consumidores de bairros residenciais suburbanos.

Além desses fatores, faz-se importante destacar que o advento do automóvel e da geladeira permitiu o maior estoque de alimentos nas residências e a maior possibilidade de deslocamento e de escolha do consumidor (Pintaudi, 
2002). O automóvel fez com que as famílias ultrapassassem o limite do bairro no momento de fazer as compras, enquanto a geladeira propiciou a compra de alimentos perecíveis em maior quantidade, diminuindo as viagens ao mercado público e às feiras livres.

O espaço de consumo da cidade, então, expande-se para além do conhecido centro comercial, possibilitando a formação de novos núcleos nas periferias. A abertura de estradas radiais e o aumento de automóveis particulares vão incidir, diretamente, no surgimento de múltiplos subcentros periurbanos que denunciam a dinâmica e a fragmentação do território.

"A periferia, dotada de um elevado potencial de consumo, decorrente do crescimento espetacular da suburbanização, com preços de solo mais baixos que as áreas centrais e irrigada de novas acessibilidades, torna-se claramente o local mais favorável ao investimento por parte das grandes superfícies. O aumento das taxas de motorização da população, os novos estilos de vida dos indivíduos-consumidores, a integração crescente da mulher no mercado de trabalho e o aumento dos rendimentos das famílias, nomeadamente através do duplo salário, já para não falar no valor simbólico que tendem a assumir os actos de compra e do abastecimento, bem como os novos espaços onde estes se realizam, são outros fatores que alimentam esta descentralização da actividade comercial, com claro prejuízo para os centros tradicionais de comércio e serviços, entre os quais o cento da cidade constitui sem dúvida um caso paradigmático (Rodrigues et al., 2000: 16-17)."

Esse modelo de suburbanização, típico da classe média norte-americana, desenvolveu-se, com algumas diferenças, em outras cidades do mundo, onde os supermercados também proliferaram como "novos templos das mercadorias" que induzem o imaginário das pessoas para o consumo.

A "estética da mercadoria" excita no observador o desejo de posse, motivando-o a comprar (Haug, 1997). A mídia e o marketing "criam" o desejo e a "necessidade" de consumo da sociedade. Há uma manipulação em que o necessário e o supérfluo se (con)fundem.

A mídia e o marketing difundidos pelas grandes redes varejistas (como Wal-Mart e Carrefour) "globalizam" padrões de consumo, criando valores, gostos e estilos de vida semelhantes em diferentes lugares do mundo, inclusive em cidades (como Sobral) onde esses cartéis comerciais ainda não atuam, mas têm suas estratégias de vendas e métodos de gestão "copiados" por estabelecimentos menores como os supermercados.

Algumas dessas estratégias varejistas "globais" adaptadas ao comércio "local" também contribuem para a segmentação e a fragmentação do tecido urbano com a formação de subcentros terciários.

Desse modo, além dos impactos nos modos de consumo da população, os supermercados também influenciam na organização dos espaços onde se ins- 
talam, levando, dentre outros processos, ao surgimento de "novas centralidades", que são:

“[...] espaços de grande valor pela sua localização, pela qualidade e pelo prestígio do sítio e dos edifícios; são os sítios mais adequados para os negócios, que oferecem maior qualidade de vida às famílias, que propiciam maiores economias. Fonte apetecível de acumulação, atraem investimentos e empresas (Salgueiro, 2006: 15)."

As avenidas John Sanford e Dr. José Arimatéia Montes e Silva (doravante chamada "Avenida do Contorno", como é mais conhecida) são, hoje, "espaços de grande valor" comercial e imobiliário em Sobral, consolidando-se como subcentros funcionais que atraem supermercados, bancos, academias de ginástica, salões e clínicas de beleza, empresas e lojas de informática, postos de combustíveis, cyber's cafés, bares, lanchonetes, restaurantes, etc. Ao mesmo tempo, cresce a especulação imobiliária nessas avenidas e as disparidades entre o comércio tradicional e as "modernas" formas comerciais, conforme analisaremos a seguir.

\section{OS SUPERMERCADOS PINHEIRO E SUPER LAGOA DE SOBRAL: FORMATO, MIX DE PRODUTOS E SERVIÇOS}

Nas últimas décadas, a cidade de Sobral tem apresentado novos dinamismos territoriais provocados pelo incremento das atividades secundárias e terciárias na sua economia. Localizada na porção noroeste do Ceará, a $230 \mathrm{~km}$ da capital Fortaleza, Sobral possui 176.895 mil habitantes (segundo a Contagem da População de 2007) que a enquadram na categoria de cidade média, de acordo com os critérios adotados pelo Instituto Brasileiro de Geografia e Estatística (IBGE, 2008).

Para o IBGE, as cidades de porte médio são aquelas que apresentam entre 100 e 500 mil habitantes. Porém, esta definição compartilhada por Santos (1998) está longe de ser consensual entre os pesquisadores e os órgãos de planejamento e estatística. Contesta-se que o critério demográfico não é suficiente para determinar as funções e a posição de uma cidade na hierarquia de uma rede urbana. Além disso, os parâmetros demográficos mínimos e máximos para definir uma cidade média também variam no Brasil e em outros países (Costa, 2002).

Nas pesquisas desenvolvidas pelo Instituto de Pesquisa Econômica Aplicada (IPEA), por exemplo, Andrade e Serra (1997) definem as cidades médias como centros intermediários cuja população urbana está entre 50 e 500 mil habitantes. Já para a Organização das Nações Unidas (ONU), as cidades médias são aquelas com população entre 100 mil e 1 milhão de habitantes.

Sobral se destaca no contexto da rede urbana cearense não apenas pelo quantitativo populacional que apresenta, mas, sobretudo, pelas atividades secun- 
dárias e terciárias que a tornam um "centro regional" para onde converge a população de cerca de cinqüenta municípios do Norte do Ceará.

"A extensão do raio de influência de Sobral justifica-se pelo quadro de serviços: bancários, escolares, médicos, expansão do comércio e sistema rodo-ferroviário. A localização de Sobral entre zonas geoeconômicas diferentes [litoral, serra e sertão] contribui para a sua função de centro catalisador e distribuidor de produtos provenientes do sertão (Souza, 1977: 64)."

Desde o início do século XVIII, Sobral se tornou um importante centro de comércio atacadista e varejista. O charque, o couro, o algodão, os óleos vegetais, a cera e o chapéu de palha de carnaúba (Caracristi, 1999) foram os principais produtos que, ao longo do tempo, inseriram a cidade nas redes do comércio mundial.

No final do século XIX, a construção da ferrovia permitiu o escoamento do algodão produzido no sertão para os portos do litoral, transformando Sobral em um importante "nó de tráfego" da rede urbana regional. A abertura e a ampliação da malha viária, no último século, reforçam sua posição geográfica, tendo a BR-222 como principal eixo do entroncamento que liga Sobral a diversas cidades do Ceará e também a outros Estados como o Piauí (fig. 1).

Mais recentemente, a instalação de grandes indústrias como a Fábrica de Cimento Portland (1964) e a Grendene (1993) redefiniram o papel de Sobral na hierarquia da rede urbana cearense (Maria Júnior, 2004), assim como influenciaram na expansão e na modernização das atividades de comércio e de serviço. "O território vai acolhendo a implantação de rede de fibra ótica, TV por assinatura, internet banda larga, cyber café, lan house, fast food, acréscimo de sinais

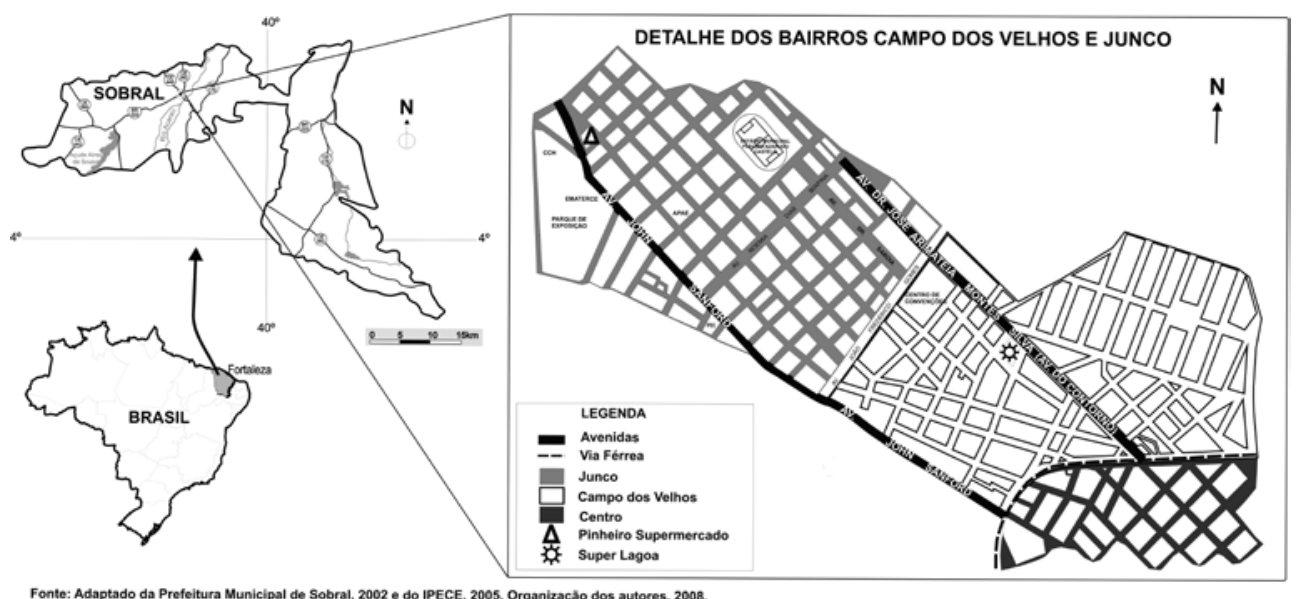

Fig. 1 - Localização dos supermercados em Sobral Fig. 1 - Location of Sobral's supermarkets 
de telefones celulares, etc. Assim, vai se redesenhando o mapa da cidade" (Holanda, 2007: 134).

Logo, Sobral passou a atrair uma mão-de-obra qualificada (como os técnicos, engenheiros, professores universitários, etc.) que se soma aos empresários e à classe média já existente, provocando um aumento no poder de consumo da população e, consequentemente, nas formas de comércio da cidade.

A cidade de Sobral é dividida em 24 bairros que não só revelam a divisão político-administrativa da sede do município, mas também a segregação sócio-espacial existente. Os maiores adensamentos populacionais estão nos bairros do Centro, Terrenos Novos e Padre Palhano. Esses dois últimos, juntamente com Alto do Cristo, Dom José, COHAB I e II, são os bairros que concentram a população mais carente e onde a oferta de comércio e de serviços é mais deficitária.

Em oposição, os bairros mais nobres (Centro, Derby, Colina da Boa Vista, Junco e Campo dos Velhos) são aqueles que mais atraem os investimentos do Poder Público, do capital imobiliário e comercial, a exemplo dos supermercados Pinheiro e Super Lagoa, instalados em Julho e Novembro de 2003, nas Avenidas John Sanford (bairro do Junco) e do Contorno (bairro Campo dos Velhos), respectivamente. Eles se localizam nessas duas importantes avenidas radiais da cidade, fora da área central que, na sua porção oeste, é delimitada pela via férrea (fig. 1).

O Pinheiro e o Super Lagoa inauguraram neste centro regional do sertão norte cearense o sistema de auto-serviço, com check-outs informatizados, amplos estacionamentos, espaços para recreação infantil, áreas de depósito com temperaturas adequadas às classes de produtos, seções de frios, laticínios, mercearias e padarias.

Os supermercados são as mais "modernas" formas comerciais de Sobral, pois ainda não existem nessa cidade média hipermercados e shopping centers. Ambos os supermercados apresentam estruturas de mini-shoppings que possuem a loja âncora e os demais estabelecimentos de apoio, além de áreas climatizadas que proporcionam o bem-estar dos cidadãos nos momentos das compras.

Com estruturas mais sofisticadas que os mercantis $^{6}$, o Pinheiro e o Super Lagoa aumentaram a concorrência com esses estabelecimentos menores e levaram muitos deles, inclusive, a melhorar seus serviços e ampliar suas lojas - como ocorrido com o Rainha e o Alan Supermercado que reformaram suas matrizes e inauguraram, recentemente, filiais mais modernas.

Em entrevistas realizadas com as gerências dos supermercados Pinheiro e Super Lagoa, identificamos que o primeiro grande desafio dos empresários foi procurar locais ideais para instalarem os empreendimentos. O processo de sele-

6 Denominação local atribuída a pequenos estabelecimentos de gêneros alimentícios que tanto correspondem às lojas de sortimento limitado ("tradicionais" mercearias), quanto aos supermercados compactos de até $700 \mathrm{~m}^{2}$ com média de 4.000 itens. 
ção dos bairros foi realizado através de pesquisas que constataram que a área central da cidade não seria viável, considerando sua aglomeração, o maior preço do uso solo, a tendência de aumento de congestionamentos, as dificuldades para instalar amplos estacionamentos particulares e para a descarga de mercadorias. Os principais critérios adotados para a escolha dos bairros do Junco e Campo dos Velhos foram: alto potencial de demanda, acesso fácil à população e ampla área para estacionamento particular.

Essas estratégias de localização dos supermercados junto às infra-estruturas de circulação que lhes favorecem o acesso, reforçam as observações de Spósito (1999: 29) de que:

"O processo de concentração econômica dos grandes grupos, que atuam no setor comercial e de serviços e daqueles que atuam no setor da produção imobiliária, implica novas escolhas em termos de estratégias econômicas e locacionais, que se expressam na estrutura urbana mudando [...] as relações entre o centro, as áreas pericentrais e a periferia."

Após a instalação dos supermercados e a recente ampliação das avenidas John Sanford e do Contorno, essas vias têm se tornado os principais "eixos comerciais e de expansão da cidade", a qual cresce mais no sentido sudoeste, em direção à Serra da Meruoca.

Os supermercados Pinheiro e Super Lagoa são filiados à Super Rede (Rede Comercial de Compras no Atacado) e mantêm parcerias com algumas empresas da região norte cearense. No Estado, já existem dezessete redes e associações de negócios atuando cooperativamente.

Uma das vantagens do associativismo é a possibilidade de oferta de produtos que levam o nome dos estabelecimentos varejistas ou das redes. Essas pequenas redes se unem para enfrentar a concorrência com as grandes (como Wal-Mart, Carrefour, Pão de Açucar, Bompreço) que se expandem especialmente nas metrópoles e nas cidades médias brasileiras.

Por serem redes nacionais ou mundiais, grupos como o Pão de Açúcar e o Carrefour (que têm mais de 9.000 lojas espalhadas em 25 países - Silva, 2003), conseguem comprar as mercadorias em maior quantidade, a baixo preço, fazendo com que ofereçam mais promoções e ofertas aos consumidores, aumentando a concorrência com os supermercados e os pequenos comerciantes.

Os supermercados analisados ainda detêm pouca variedade de produtos da Super Rede expostos em suas gôndolas. Para investir em mercadorias próprias, os supermercados não podem deixar de lado fatores como embalagem, qualidade, exposição e variedade. Esses são elementos determinantes na compra, para efeitos de comparação com outras marcas. A marca própria precisa estar $20 \%$ mais barata que a marca tradicional e mantendo a mesma qualidade. Com isso, busca-se fidelizar clientes com as marcas próprias, criando um diferencial frente aos concorrentes.

O Pinheiro Supermercado possui quatro lojas na capital Fortaleza e mais três espalhadas nos municípios de Quixadá, Itapipoca e Sobral. A loja de Sobral, 
localizada na Avenida John Sanford, é a maior do grupo com $1.500 \mathrm{~m}^{2}$ de área de venda, sendo estruturada com equipamentos de ultima geração e um design moderno, comparando-se aos outros estabelecimentos do grupo. A administração firmou parcerias com o SEBRAE (Serviço Brasileiro de Apoio às Micro e Pequenas Empresas), CDL (Câmara de Dirigentes Lojistas), SESC (Serviço Social do Comércio), Prefeitura Municipal e construiu catorze estabelecimentos de serviços agregados à loja principal, dentre eles, Banco 24 horas, Correios, Salão de Beleza, Restaurante, lanchonete etc. Além disso, o prédio abriga duas salas de cinema com capacidade de 237 lugares, homenageando um filho ilustre de Sobral - $\mathrm{o}$ ator Renato Aragão. Esse empreendimento comercial totaliza uma área de $5.000 \mathrm{~m}^{2}$ (fig. 2).

O Super Lagoa também tem quatro lojas em Fortaleza, duas em Juazeiro do Norte e somente uma em Sobral (na Avenida do Contorno) com uma área de venda de $1.200 \mathrm{~m}^{2}$. Anexo ao prédio desse supermercado há outros estabelecimentos comerciais e de serviços como restaurante, posto de combustíveis, locadora e academia que são de proprietários independentes (fig. 3).

Em Sobral, o Pinheiro e o Super Lagoa vêm ampliando as estratégias de marketing e modernizando suas logísticas para atrair mais clientes. Eles, freqüentemente, vinculam campanhas focadas nas promoções de preços, através de distribuição de encartes na cidade (duas a três vezes por mês), nos quais procuram chamar a atenção da população através de slogans atrativos como: "se você quer preços baixos a super rede é o lugar", "campeã em economia, aqui você é quem ganha", "aqui tem tudo, venha aproveitar".

Outra estratégia é o "dia de oferta" de alguns produtos que têm seus preços reduzidos. Por exemplo, em ambos os supermercados, segunda e terça são "os dias das frutas e verduras"; quarta e quinta acontece o "festival da carne".

A comunicação visual interna é outro aspecto dos supermercados que merece constante atenção das gerências. Os layouts do Pinheiro e Super Lagoa mudam

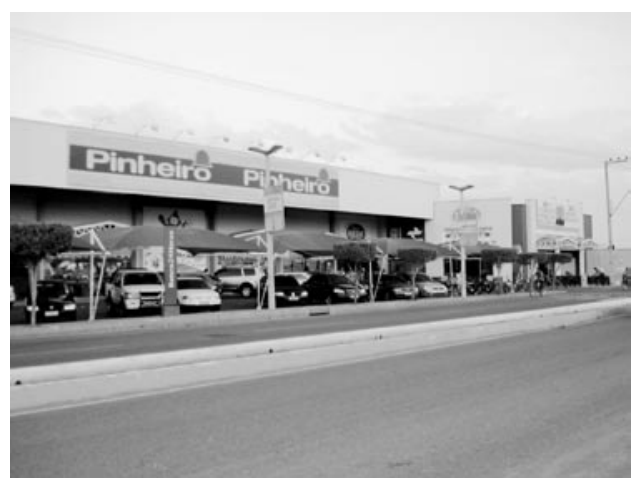

Fig. 2 - Supermercado Pinheiro Fig. 2 - "Pinheiro" Supermarket Fonte: Arquivo dos autores, 2007

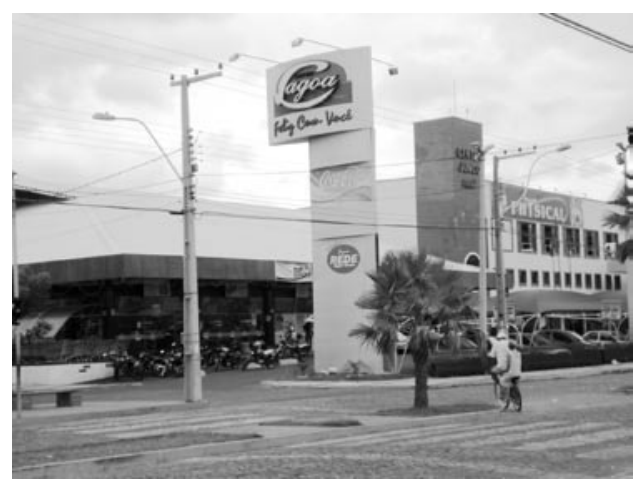

Fig. 3 - Super Lagoa

Fig. 3 - "Lagoa" Supermarket

Fonte: Arquivo dos autores, 2007 
sazonalmente e de acordo com algumas datas festivas como a Páscoa, São João e o Natal. Todos os meses, ocorrem pequenas mudanças nas pontas das gôndolas, que devem ser organizadas para que o cliente possa identificar rapidamente o que procura.

Contudo, existe um layout e um padrão de organização espacial que prevalece por mais tempo na estrutura interna dos supermercados, conforme podemos observar na figura 4, em que as seções de frios, laticínios, peixaria/açougue e orgânicos estão no fundo da loja, enquanto a padaria e os hortifrutigranjeiros ficam nas laterais.

Logo na entrada, avistam-se os caixas e, em destaque, as "promoções" que encabeçam as gôndolas do centro da mercearia e podem, inclusive, se espalhar por toda a loja. Esta é a estrutura mais convencional do espaço interno dos Supermercados Pinheiro e Super Lagoa.

Os dois supermercados em apreço oferecem as cinco seções básicas de produtos (mercearia, hortifrutigranjeiros, açougue/peixaria, frios, laticínios e padaria). Não existem farmácia, livraria, eletro-eletrônicos, vestuário e outros produtos diversificados que caracterizam os hipermercados.

Nos supermercados Pinheiro e Super Lagoa também há programas de fidelização como a oferta de cartões preferenciais de compras, bônus de crédito, vendas a prazo até sessenta dias e entrega em domicílio com o intuito de atrair a preferência dos clientes.

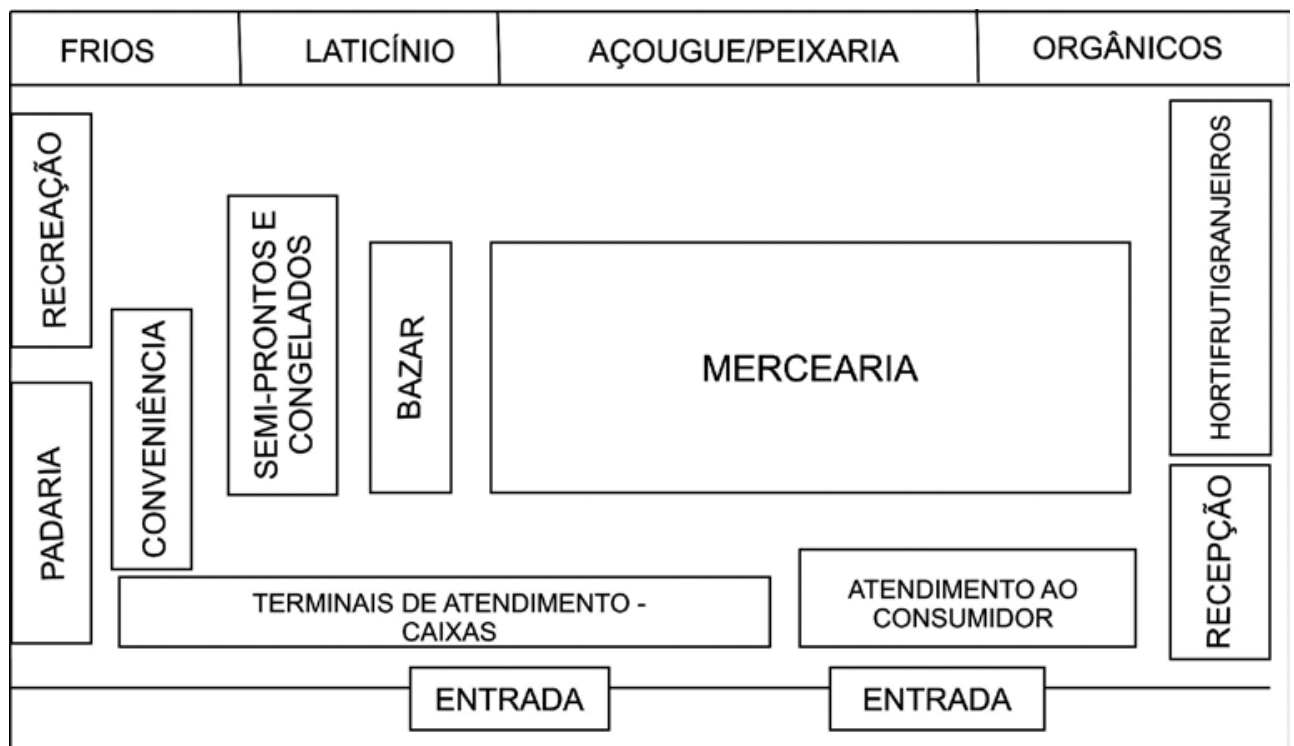

Fig. 4 - Layout convencional dos supermercados Pinheiro e Super Lagoa Fig. 4 - Conventional layout of the "Pinheiro" and "Lagoa" supermarkets Fonte: Adaptado de Borges (2006) 
Com essas estruturas e estratégias, os supermercados Pinheiro e Super Lagoa têm acirrado a concorrência com as tradicionais formas de comércio da cidade (mercantis, mercearias, padarias, mercado público, etc.), sobretudo daquelas que se encontram nas suas adjacências, nas Avenidas do Contorno e John Sanford - como analisaremos adiante.

\section{TRANSFORMAÇÕES E RESISTÊNCIAS NO ESPAÇO URBANO DE SOBRAL}

Os dados coletados na Secretaria da Fazenda do Estado (SEFAZ) atestam o crescimento das atividades econômicas em Sobral. Entre 1996 e 2006, houve um acréscimo de 408 para 3.724 estabelecimentos econômicos cadastrados, que estavam distribuídos entre os ramos comercial (58\%), de serviços (33\%) e industrial (9\%) (Holanda, 2007: 134). A preponderância das atividades comerciais no município também foi responsável para que esse registrasse, em 2001, o maior Índice Potencial de Consumo do interior do Ceará, segundo a Gazeta Mercantil (Assis et al., 2007).

Em Sobral, os "dois circuitos da economia urbana" (Santos, 1979) revelam na paisagem as desigualdades sócio-espaciais. No "circuito superior" predominam os supermercados, concessionárias, bancos, lojas de informática, eletro-domésticos, clínicas médicas especializadas, etc.; no "circuito inferior", as mercearias, mercado público, feira livre, ambulantes, trabalhadores informais, escolas e hospitais públicos, entre outros.

O centro da cidade ainda é o bairro onde os dois circuitos têm maior expressão. Porém, a concentração do comércio na área central tem sido acompanhada, na última década, pela expansão para outros bairros como Junco e Campo dos Velhos (quadro II). "A distribuição do comércio pelo território passa por modificações. Em 1996, 84,54\% dos comércios registrados estavam no bairro do Centro; em 2006, 72,79\%, ou seja, embora os registros do comércio do Centro sejam crescentes, a busca pelos espaços dos bairros é também representativa" (Holanda, 2007: 144-145).

Quadro II - Distribuição do comércio em alguns bairros de Sobral - 1996/2006

Table II - Geographical distribution of retail shops in some quarters of Sobral - 1996/2006

\begin{tabular}{lrr}
\hline Bairros & $\mathbf{1 9 9 6}$ & $\mathbf{2 0 0 6}$ \\
\hline Centro & 175 & 1.581 \\
Junco & 2 & 171 \\
Campo dos Velhos & 1 & 57 \\
\hline
\end{tabular}

Fonte: Dados do CNAE - Classificação Nacional de Atividades Econômicas Organização dos autores adaptada de Holanda (2007: 146) 
Em grande parte, isso se deve ao aumento do número de carros e motos particulares que permitem à população local maior deslocamento entre o centro e a periferia. À medida que a cidade cresce, a descentralização também aumenta, levando à formação de subcentros terciários nos bairros do Junco e Campo dos Velhos, especialmente nas avenidas John Sanford e do Contorno onde estão localizados os supermercados Pinheiro e Super Lagoa.

Buscamos, então, analisar a influência desses supermercados nas tradicionais formas de comércio do circuito inferior que se encontram nas duas avenidas em apreço. Para tanto, selecionamos nos trabalhos de campo uma amostra aleatória simples de 14 estabelecimentos comerciais entre as duas avenidas. Aplicamos entrevistas semi-estruturadas com os pequenos comerciantes, mesclando técnicas de pesquisa quantitativa e qualitativa que nos permitissem construir um perfil sócio-econômico dos proprietários e avaliar suas opiniões sobre os supermercados investigados.

Na Avenida John Sanford, entrevistamos, em Junho de 2007, nove pequenos comércios (5 mercearias, 3 mercantis e 1 padaria) desse importante eixo viário de Sobral que é mais extenso de que a Avenida do Contorno, onde pesquisamos cinco estabelecimentos (4 mercearias e 1 padaria) (fig. 1).

$\mathrm{O}$ uso do solo em ambas as avenidas é tomado por residências e, sobretudo, por imóveis de comércio e serviços. Na Avenida do Contorno estão localizados importantes equipamentos urbanos, como o Centro de Convenções, o SESI (Serviço Social da Indústria), a seção local da OAB (Ordem dos Advogados do Brasil), o Parque da Cidade e algumas escolas públicas e privadas. Nos últimos anos, registra-se nessa avenida a concentração de salões de beleza e de lojas de produtos e serviços de informática, como internet a rádio e sem fio (wireless). A expansão dessas atividades e a inauguração do Super Lagoa, em 2003, aumentaram a especulação imobiliária no bairro Campo dos Velhos, prolongando-se pelo bairro do Junco.

Segundo levantamentos feitos na Prefeitura Municipal de Sobral, entre 2002 e 2007, houve um acréscimo no total de imóveis de 519 para 719 (38\%). no bairro do Junco, e de 1.680 para 2.275 (35\%) no Campo dos Velhos. Nos dois bairros, os imóveis comerciais cresceram mais que os residenciais, no mesmo período, ficando o Junco com uma variação de $47 \%$ e o Campo dos Velhos com 93\% (quadro III).

Quadro III - Imóveis dos bairros Campo dos Velhos e Junco - 2002/2007*

Table III - Real-estate properties in the Campo dos Velhos and Junco quarters

\begin{tabular}{|c|c|c|c|c|c|c|}
\hline \multirow{2}{*}{ Ano } & \multicolumn{3}{|c|}{ Junco } & \multicolumn{3}{|c|}{ Campo dos Velhos } \\
\hline & residencial & comercial & total & residencial & comercial & total \\
\hline 2002 & 412 & 107 & 519 & 1.343 & 337 & 1.680 \\
\hline 2007 & 562 & 157 & 719 & 1.626 & 649 & 2.275 \\
\hline Evolução & $36 \%$ & $47 \%$ & $38 \%$ & $21 \%$ & $93 \%$ & $35 \%$ \\
\hline
\end{tabular}

Fonte: Dados da Prefeitura Municipal de Sobral, 2007. Organização dos autores

*Dados baseados nos lançamentos de IPTU 
A Avenida John Sanford também possui importantes equipamentos urbanos (como o Hospital-Escola de Saúde da Família, a EMATERCE - Empresa de Assistência Técnica e Extensão Rural do Ceará - e o Centro de Ciências Humanas da UVA); porém, apresenta maior heterogeneidade sócio-espacial que é facilmente visualizada pelo número de habitações e de pequenos estabelecimentos comerciais que atendem às classes sociais mais baixas dos bairros Terrenos Novos e COHAB 3, que se situam no entorno.

Nas entrevistas realizadas, constatamos que todos os pequenos comerciantes começaram seus negócios com capital próprio e os mantêm como o principal meio de renda. Eles mantêm seus estabelecimentos abertos mais de dez horas por dia, registrando uma concentração das vendas nas primeiras semanas do mês quando ocorre a maior circulação de dinheiro devido aos pagamentos dos programas sociais do Governo Federal, dos aposentados, dos servidores públicos estaduais e municipais, assim como dos funcionários das grandes indústrias da cidade - a exemplo da Grendene que emprega mais de dez mil trabalhadores.

Os pequenos comerciantes utilizam várias estratégias para enfrentar a concorrência entre eles e especialmente com os supermercados. Eles oferecem diferentes meios e oportunidades de pagamento a prazo, fazem entrega em domicílio, estabelecem um relacionamento direto e mais próximo com o cliente, além de possíveis descontos no ato do pagamento.

Uma peculiaridade do pequeno comércio que merece destaque é a "permanência" de anotações em cadernetas das vendas para pagamentos quinzenais ou mensais, especialmente para aposentados e funcionários públicos. Por meio desta prática são estabelecidas relações de "pessoalidade" e afinidade entre comerciantes e clientes, já que o dono do comércio passa a conhecer melhor a realidade do seu consumidor.

Os entrevistados abastecem seus comércios com os atacadistas de Sobral, com vendedores de Fortaleza e da Região Norte do Estado, assim como nos supermercados em análise, quando esses oferecem boas promoções para venda a atacado. Os comerciantes afirmaram que é insignificante a quantidade de mercadorias perdidas por comprarem em pequenas quantidades, de acordo com a procura dos clientes.

Dentre as diversas dificuldades enfrentadas por eles, destacaram o pequeno número de clientes, a falta de dinheiro da população (daí muitos "resistirem" com as compras "fiado"), a falta de assessorias, capacitações e de apoio financeiro do Poder Público e dos bancos (que ainda têm juros muito altos). Tudo isso acarreta baixos lucros nas vendas e, consequentemente, poucos investimentos em reformas ou ampliações do estabelecimento.

Essas dificuldades acirram ainda mais a concorrência com os supermercados, levando os pequenos comerciantes a registrarem uma média de $30 \%$ de queda nas vendas. Os antigos clientes das classes mais abastadas que, antes dos supermercados, compravam nesses pequenos estabelecimentos, hoje fazem suas compras mensais no Pinheiro ou Super Lagoa e, com menos freqüência, adqui- 
rem um ou outro produto de reposição (como frios, pão, frutas, etc.) nos momentos de translado casa-trabalho em que passam pelas avenidas em apreço.

Contudo, a instalação dos supermercados em Sobral é avaliada como positiva pela grande maioria (12) dos entrevistados, como pode ser observado em alguns depoimentos abaixo:

Sobral já é uma cidade desenvolvida, com grande população que precisa de supermercados desse porte. (Comerciante da Av. do Contorno)

Os supermercados trazem mais fonte de emprego, mais comércio, atraem mais pessoas, gerando circulação de capital. (Comerciante da Av. John Sanford)

Depois deles, aumentou o bairro e valorizou toda a região. (Comerciante da Av. John Sanford)

Eles também vendem no atacado, favorecendo as compras e as promoções para os pequenos comerciantes. Eles inovam nas técnicas de trabalho e servem de modelo para nós. (Comerciante da Av. do Contorno)

Esse último depoimento demonstra que embora o pequeno comércio e as grandes superfícies varejistas sejam concorrentes diretos e mantenham características distintas (conforme apresentado no quadro I), eles também estabelecem parcerias, difundem modelos e estratégias de vendas, levando muitos supermercados a segmentarem seus pontos de venda nos centros e nas periferias, oferecendo serviços personalizados como compras por telefone, internet e até entregas em domicílios - como fazem o Pinheiro e o Super Lagoa para atrair consumidores que não dispõem de um automóvel particular.

Concorrência e complementaridade são, inclusive, características intrínsecas aos circuitos superior e inferior que abarcam, respectivamente, os supermercados e o pequeno comércio, como ressalta Santos (1979: 204):

"Os dois circuitos não são dois sistemas isolados e impermeáveis entre si, mas ao contrário, estão em interação permanente. [...] Relações de complementaridade e concorrência resumem toda a vida do sistema urbano. Os dois subsistemas estão em permanente estado de equilíbrio instável. Sua complementaridade não representa outra coisa senão um momento privilegiado de uma certa evolução que conduz a uma dialética dos dois circuitos."

Em Sobral, os dois comerciantes que avaliaram como negativa a instalação dos supermercados destacaram:

Os pequenos mercantis e mercearias não conseguem concorrer com estes supermercados que prejudicam o pequeno e o médio comerciante. (Comerciante da Av. do Contorno) 
Grande parte da renda do Lagoa e do Pinheiro vai para Fortaleza, apenas sugando a renda da população daqui. (Comerciante da Av. do Contorno)

Apesar dessas divergências, todos os entrevistados reconheceram os supermercados como importantes agentes de transformação do comércio e da cidade. Três entrevistados ainda ressaltaram que a presença do Pinheiro e do Super Lagoa em Sobral influencia nas ações do Poder Público Municipal, o qual tem intensificado as obras e instalações de equipamentos nos bairros do Junco e Campo dos Velhos.

\section{CONCLUSÃO}

Os dados e as informações apresentadas confirmam que a chegada dos supermercados Pinheiro e Super Lagoa em Sobral vem provocando transformações e resistências nas avenidas e bairros onde estão localizados, especialmente com a descentralização das atividades terciárias e o aumento do mercado imobiliário.

Uma reestruturação intra-urbana se inicia em Sobral com a instalação desses supermercados nas avenidas John Sanford e do Contorno, provocando a formação de novas centralidades nos bairros do Junco e Campo dos Velhos. Nesses bairros, torna-se premente um melhor planejamento do Poder Público Municipal para controlar o crescimento desordenado e a especulação imobiliária que se acentua, aumentando ainda mais a segregação entre pobres e ricos e seus espaços de moradia e consumo na cidade.

Os grandes investimentos públicos em serviços e equipamentos urbanos continuam privilegiando as áreas "nobres" da cidade, onde o capital imobiliário-comercial se reproduz intensamente - como a duplicação da Avenida John Sanford (que dá acesso ao Pinheiro Supermercado) e a construção do Parque da Cidade (no entorno do Super Lagoa).

Os supermercados também têm modificado as práticas e hábitos de consumo da população sobralense, sobretudo das classes mais abastadas que procuram nesses estabelecimentos maior conforto, segurança, variedade de produtos e serviços, mais opções de pagamento e, inclusive, maior horário de funcionamento - até às 23 horas.

Porém, a população mais carente recorre, com mais freqüência, ao pequeno comércio do entorno das residências, já que as linhas e os serviços de transporte público em Sobral são bastante deficientes. Muitas pessoas ainda usam as tradicionais relações de compra e venda baseadas na confiança e na anotação em cadernetas para pagamento na quinzena e no início do mês. Esta é, na verdade, a principal estratégia de "resistência" dos pequenos comerciantes da cidade, como as mercearias, as padarias e os mercantis pesquisados.

Apesar de sofrerem os maiores impactos com instalação dos supermercados em Sobral, os pequenos comerciantes consideram que a vinda de grandes unidades comerciais é um processo inevitável que acompanha o próprio crescimento 
da cidade. Eles ainda reconhecem que os supermercados têm lhes "despertado" a necessidade de inovar, de melhorar suas instalações e de aumentar a variedade de produtos.

Sendo assim, cabe aos pequenos comerciantes buscar na Prefeitura de Sobral apoio e parcerias com a CDL, SESC, SEBRAE, bancos e outras instituições que ofereçam capacitações, financiamentos e orientações para que "resistam" à concorrência com os supermercados e com outras "modernas" formas comercias que, brevemente, estarão ampliando o espaço de consumo e a segregação social nessa cidade média do Nordeste brasileiro.

\section{BIBLIOGRAFIA}

Andrade T A, Serra R V (1997) O recente desempenho das cidades médias no crescimento populacional urbano brasileiro. IPEA, Rio de Janeiro. (Textos para discussão, n. 554).

Assis L F, Araújo F F, Gomes M F (2007) A terciarização da cidade média de Sobral e suas influências no comércio das cidades pequenas de Cariré e Varjota - CE. Revista da Casa da Geografia de Sobral, 8/9: 123-140.

Barata Salgueiro T (2006) Oportunidades e transformação na cidade centro. Finisterra - Revista Portuguesa de Geografia, XLI(81): 9-32.

Borges A R (2006) As estratégias do supermercado de vizinhança para conquistar clientes. http:// www.artigocientifico.com.br [Acedido em 23 de Setembro de 2006].

Caracristi I (1999) A indústria chapeleira sobralense. Revista da Casa da Geografia de Sobral. Sobral-CE: UVA, 1(1): 35-44.

Corrêa R L (2002) O espaço urbano. 4. ed., Ática, São Paulo.

Corrêa R L (2001) Trajetórias geográficas. 2. ed. Bertrand Brasil, Rio de Janeiro.

Costa E M (2002) Cidades médias: contributos para a sua definição. Finisterra - Revista Portuguesa de Geografia, XXXVII(74): 101-128.

Fernandes J A R, Cachinho H, Ribeiro C V (2000) Comércio tradicional em contexto urbano: dinâmicas de modernização e políticas públicas. Observatório do Comércio. http://www.dgcc. pt/166.htm\#12 [Acedido em 28 de Setembro de 2008].

Haug W F (1997) Crítica da estética da mercadoria. EDUNESP, São Paulo.

Holanda V C C (2007) Modernizações e espaços seletivos no Nordeste brasileiro. Sobral: Conexão Lugar/Mundo. Tese de doutoramento em Geografia Humana apresentada à Faculdade de Filosofia, Letras e Ciências Humanas, Universidade de São Paulo. São Paulo.

IBGE (Instituto Brasileiro de Geografia e Estatística) (2008) Contagem da população de 2007. http://www.ibge.gov.br [Acedido em 22 de Abril de 2008].

Maria Júnior M (2004) Cidades médias: uma abordagem da urbanização cearense. Dissertação de mestrado em Geografia apresentada à Universidade Estadual do Ceará. Fortaleza.

Pintaudi S M (2002) A cidade e as formas de comércio. In Carlos A F A (org.) Novos Caminhos da Geografia. Contexto, São Paulo: 143-159.

Pintaudi S M (1981) Os supermercados na grande São Paulo: contribuição ao estudo da transformação do comércio varejista de gêneros alimentícios nas grandes metrópoles. Dissertação de mestrado em Geografia apresentada à Faculdade de Filosofia e Ciências Humanas, USP. 
Santos M (1998) A urbanização brasileira. 4. ${ }^{a}$ ed. Hucitec, São Paulo.

Santos M (1979) O espaço dividido: os dois circuitos da economia urbana dos países subdesenvolvidos. Francisco Alves, Rio de Janeiro.

Silva C H C (2003) As grandes superfícies comerciais: os hipermercados Carrefour no Brasil. GEOUSP - Espaço e Tempo, 14: 89-106.

Souza M S (1977) Contribuição ao estudo da hierarquia urbana do Ceará. Revista Brasileira de Geografia, 39(3): 54-86.

Spósito M E B (1999) A gestão do território e as diferentes escalas da centralidade urbana. Revista Território, III(4): 29-37.

Strohaecker T M (1988) A zona periférica ao centro: uma revisão bibliográfica. Revista Brasileira de Geografia, 50(4): 171-183. 